\title{
Thinking and Informing: A Reality-check on Class Teachers and Teacher Librarians
}

\author{
JAMES HENRI \\ Faculty of Science and Agriculture, \\ Charles Sturt University, \\ Wagga Wagga, N.S.W., Australia \\ jhenri@csu.edu.au
}

\begin{abstract}
The literature suggests that twenty first century schools must pay as much attention to how students learn as they do to what students learn. Part of the 'how students learn' encompasses attempts to address student mastery of the processes of becoming informed. At one time it was considered the role of the teacher librarian to teach students information skills or an information process. At one time it was assumed that class teachers could teach these skills and this process. In more recent times it has been suggested that teacher librarians and class teachers must form partnerships to enable the building of a school culture that facilitates an emphasis on ways of learning rather than on what is learned.

A number of writers have suggested that the key agent in the fight for information literate schools is the teacher. The teacher is at the front line working with students on a day to day basis and influencing student expectation and behaviour. As teaching practice changes from teacher focused quantitative approaches to student centred and more qualitative approaches the importance of the teacher as role model and mentor becomes paramount.
\end{abstract}

A common thread to these approaches is the assumption that class teachers and /or teacher librarians are themselves information literate. That is, it is assumed that teachers (and especially teacher librarians) have mastered the processes of becoming informed. It is assumed that they work with an information-processing model (whether that entails a formal model or a systematic approach) and that they themselves employ higher order thinking skills when undertaking complex information tasks.

This paper reports on a project that tested the validity of these assumptions. It seeks in part to identify whether or not teachers understand the information process and whether they are able to use a process to undertake a complex information task. Are teachers equipped to act as role model and mentor to their students? Does being employed as a teacher librarian (as distinct from being a qualified teacher librarian) make a difference to understanding, and use of, an information process? 


\section{$\underline{\text { Purpose of the Study }}$}

The purpose of this study was to determine whether or not teachers (class teachers and teacher librarians) demonstrate a sophisticated level of information literacy when they undertake a sophisticated information task.

The presentation that this paper supports will focus on parts of the study including an analysis of how teachers think, their levels of confidence about undertaking information tasks, and their cognitive and affective practice.

\section{Review of the Literature}

Despite the growing number of information seeking behaviour studies on a range of professions and professionals we know very little about the information seeking behaviour of teachers. An early study indicated that the information that teachers believe they ought to have, would like to have, or have requested is most likely to be of a practical nature. The information is most likely to be classroom orientated and related to a particular teaching topic (Hounsell, Martin, Needham, and Jones 1980). Studies by Juchau (1984) and Dillon (1992) support this contention and indicate that teachers are not particularly inventive in their search for professional development information.

Beswick (1987) and O'Connell (1997) note that teachers tend to use few information sources and find information solutions by employing an established pattern. We know that teachers have a few trusted favourite tools of trade and that their information sources are largely limited to their colleagues, the school library, and home reference library. It is also known that teachers tend to be more confident in the print world than in the electronic world (Henri, 1997).

A consistent thread throughout the literature is that information literacy must be a priority with teachers if it is to be a reality for students. Doyle (1994) argued that:

Teachers are the most critical key to student attainment of information literacy...They must become information literate themselves, comfortable with the variety of resources as well as the process of assessing, evaluating and using information.

In like fashion Hughes (1998: 94-96) suggested that:

The teacher must make information literacy a priority in planning and implementing the day to day program. Long range plans must include information literacy....The commitment must be deep on the part of the classroom teacher to enable students to internalise the information problem-solving process and learn the skills....Perhaps it is time for teachers to listen to their students pleas for help in deciding what's important in the sea of information they can now access through electronic technology and realise that building information problem-solving skills and process is essential to solving this learning/teaching problem. Perhaps it is time for teachers to take another look at the focus of their teaching and realise that they need to help students to find and use a model for problem-solving, for critical thinking. Perhaps it is time for teachers to refocus their approach and connect with teacher librarians... 
Candy (1995) was forceful when he claimed that: 'until teachers include information literacy skills in their own practice, they will be unable to lead the process for others'. Indeed Learning for the future (1993) highlights the place of the teacher in the information process but fails to recognise that fully involving teachers with information products is no guarantee that these teachers will become information literate.

Moore (1998: 90-91) concluded from her research the more likely reality that:

If the information climate of the schools is such that teachers do not recognise a need to look to the authority of published material, they are unlikely to extend their information skills beyond strategies of talking to other teachers and using publications to hand. This has implications for their awareness of search strategies, the challenges of information seeking in a technologically driven information world and their ability to promote information skills among children.

Staff development is a key issue in fostering information literacy in the primary schools. As shown in interview data, many teachers just did not know where to begin. Some addressed the skills as part of established good practice, but others unintentionally overlooked the challenges children faced and expected information problem solving to occur with the minimum of support.

\section{Again Moore (1998a: 123) found that:}

...most teachers believed they had "practical understanding" of information skills, but again around half of them then responded that they were unfamiliar with ways in which the process of finding and using information could be broken into steps for teaching. In one school $78 \%$ of teachers responded in this way. Where teachers did give an indication of information problem solving steps, they often focused on defining needs and locating information, without giving attention to what is done with it.

O'Connell and Henri (1997: 135) reporting on a case study into teachers' information literacy suggested that:

We know that learning for students needs to be staged so that learners can build the multiple skills required to achieve expert performance and discover the conditions under which they apply. A sound model of the information process provides these learning anchors, within an organizational framework, for the control of sequence, pacing and direction, and to provide motivation and facilitate engagement in cognitive reflection and the restructuring of information and knowledge. In this framework a teacher becomes both expert and peer, working alongside the student as co-learner and co-investigator. To be successful in this role teachers must radiate information literacy. To do this they need a sound mental model of the information seeking process in order to model good practice in education programs and to act effectively as mediator for each student or for the class.

In noting that 'little research has focussed on the teachers who it is assumed, will have information skills themselves' Wilson (1997) found in fact that this was a naïve assumption. From her study of professionals who have expectations of student teachers 
regarding information skills, and student teachers reflecting on their own information skills she found that there was:

- a lack of understanding about the term information skills

- a general inability to view information skills as generic skills in a holistic way

- an inability and/or lack of opportunity, in many cases, to reflect on abilities and shortfalls.

Wilson (1997: 72) concluded that teachers:

...need to be information literate. The study, however, suggests that the issue is bigger than this: before they know how to become information literate, they first need to appreciate why they need to become information literate. They must develop the ability to verbalize their needs and for this to happen they need time to reflect on what learning means to them in order for these needs to be clarified. Being taught about the learning process in connection with your job as a teacher is quite different from internalizing the information and applying it in a personal way.

So where is this time for reflection? The study so far indicates that it does not exist. Although the appropriate skills are recognized within curriculum guidelines, no time is apparently dedicated for ownership and review of these information skills. Teacher educators have the ideal opportunity to help student teachers gain competence and confidence in information skills because of the emphasis in the curricula...Educators are still teaching learners -- subject expertise alone does not make them teachers or effective learners

Wilson's contention that teachers are unable to provide an information literate role model is supported by O'Connell (1997) who found that teachers believed that their students ought to use the skills of the teacher librarian as an information mediator, but did not perceive the same need for themselves. Further, O'Connell suggests that teachers see students as cognitive apprentices, but themselves as mature information users not needing support from information specialists. Goodlad (1990: 669) warned that this mismatch between student and teacher behaviour is a major impediment to school improvement. He suggested that teachers must be diligent in ensuring that no attitudes, beliefs, or practices bar students from access to the necessary knowledge.

\section{Theoretical framework}

Kuhlthau's Information Search Process Model, the Self Efficacy Scale developed by Ralf Schwarzer \& Matthias Jerusalem, Bloom's Taxonomy of the Cognitive Domain, and de Bono's Six Thinking Hats provided the theoretical framework for the study.

\section{$\underline{\text { Research questions }}$}

The purpose of the research was to test the view that teachers were sufficiently information literate to be able to create an information literate environment in which students could learn from them. Indeed the literature regularly assumes that even if class teachers fall short of being information literate, that partnership with a teacher librarian will suffice to create the necessary ingredients to produce an information literate environment. Given that a 
significant proportion of teacher librarians are under-qualified is this a realistic assumption? Are teachers information literate and, therefore, capable of creating a metacognitive environment and modelling good information practice to their students? The specific questions were:

- Are teachers information literate?

- Do they believe that they are information literate?

- Do they have similar expectations, with respect to information, for their students and themselves?

- Do they use an information process model (especially do they use the model that they teach) and are they competent information users?

- Do teachers employ higher order thinking skills (or use a range of thinking hats) when they compose a research paper?

\section{METHODOLOGY}

Researchers, such as McGregor (1993) and Pitts (1994), investigating the way students perceive the research process, were able to include observation as a valuable research tool. Unfortunately it is, for all practical purposes, impossible to study teachers as researchers under the same natural conditions. In order to investigate teachers as researchers a convenience sample of teachers undertaking a research assignment was chosen. The research group consisted of 91 teachers undertaking a foundation subject in the postgraduate course work degrees in teacher librarianship at Charles Sturt University. The subject chosen (ETL401) immersed students in discussion about information literacy and the participants were either practicing class teachers or (unqualified) teacher librarians.

The project, of which the presentation is a part, employed a combination of quantitative and qualitative tools. A case study model was employed. The tools that were used to gather data were: questionnaire, self-efficacy rating, diaries, drafts, thinking logs, and think-aloud-protocols.

The information task that formed the basis of the study was an assignment (which students had 16 weeks to complete) within the subject. The question was:

The paper in your Readings by Eisenberg and Brown identifies some critical questions about the legitimacy of many of the concepts that underpin the curricular role of the teacher librarian. Your task is to analyse and discuss some of these concerns that have implications for the work of the TL with respect to information literacy, resource based learning, and cooperative planning and teaching.

Your analysis should demonstrate an understanding of the work of Kuhlthau [especially her work on the affective domain], and McGregor [especially her work on the cognitive domain], and Learning for the future [especially reference to Australian research and practice] (see Readings and texts) in so far as these tackle the issues that you choose. You should identify the implications of your findings for a school with which you are familiar and identify how teachers and TLs might address these. (ETL401:14) 
(One should note that the question is deliberately dense and difficult. It requires that the student (the teacher) be able to draw the disparate threads together. It assumes that the student will be able to form a focus and use this focus to recast the question.)

\section{$\underline{\text { Data analysis }}$}

The data that underpins this presentation was collected via self-efficacy and thinkaloud-protocols, and from diaries. Diaries were analysed using an inductive approach and coded against Kuhlthau's ISP model. Attention was paid to the cognitive and affective domains.

The self-efficacy protocols were analysed statistically. The think-aloud-protocols were transcribed from audiocassette to word and from word to NUD*IST. The text blocks were coded against Blooms taxonomy and against de Bono's six hats.

\section{Results or Findings (Preliminary)}

Kuhlthau's ISP. The study showed that teachers do not instinctively employ and information processing model. Teachers had difficulty in interpreting the research question and in making it there own.

Kuhlthau's information processing model (ISP) distinguishes between the stages of topic exploration and resource collection. This can be distinguished in behavioural terms as the difference between seeking relevant and seeking pertinent information. The critical factor on which this distinction turns is focus. The teachers in this project were given a broad and deliberately fuzzy topic and at the outset this meant that their task was vague and in need of finetuning. When confronted by the question most of the teachers went into a spin. The question was dense and included technical terms and reference to writers unknown to them. It would have been expected that initial action would be taken to clarify these elements.

The researcher expected that the teachers would seek out the Reading by Eisenberg and Brown and use it as a source of focus. The large majority of teachers, however, tackled the readings in numerical order and therefore did not enlist the support of this key tool as a preliminary sifting device in determining what was important and what was not.

The teachers found it difficult to distinguish between relevant and pertinent information. This inability lead to time wasting over analysis of items that might turn out to be irrelevant or of marginal interest. It meant that typically there was a problem of too much information.

Kuhlthau's model tracks the affective domain through a cycle of anxiety and uncertainty, optimism, confusion and frustration, through to a sense of clarity. This makes perfect sense when one considers the issue of focus. The teachers experienced the highs and lows of anxiety. Only when they read about the work of Kuhthau did they understand that this was a normal part of the information process.

Some teachers came to a focus as they sat down to write. That is the focus did not drive the search for information, it merely fashioned what was eventually used. Some 
teachers admitted that they never achieved a focus. In fact for some teachers the real agenda was actually sorting out what the lecturer wanted rather than coming to a personal understanding of the issue. Some remained uncertain about whether they had achieved this.

The problem of focus could be observed from another angle. That is some teachers could not come to a decision that they had enough information. The idea that a single silver bullet lay out there somewhere was a common attitude. A minority of teachers judged that the information process needed to be viewed pragmatically. The information task was not typically to find a solution but rather to gather evidence for a position.

\section{Model 1}

\section{Kuhlthau's ISP}

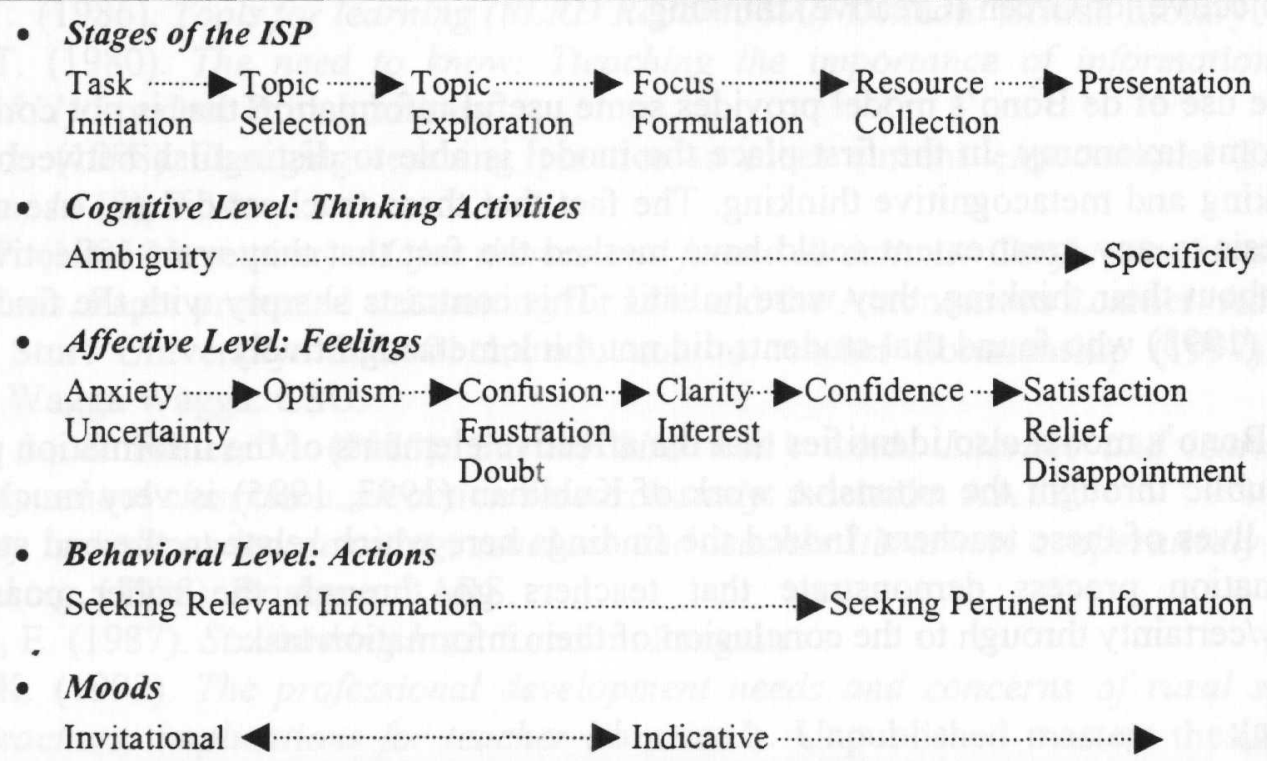

\section{Mental Models}

This study found that the teachers' use of higher order thinking skills were more pronounced than has been identified by recent studies of senior secondary students. However, the mapping against Bloom and de Bono showed that the framework used can provide somewhat different understanding. Mapped against Bloom the respondents look less metacognitive than mapped against de Bono for example.

Data indicating mental models were generated from think-aloud-protocols which were created as the participants constructed their final drafts. The teachers were asked to think aloud about why they made the decisions that they did. The data were mapped against two theoretical models: that of Bloom and that of de Bono.

\section{Bloom's Taxonomy}

On average teachers spent considerably more time on comprehension, evaluation of material, and evaluation of the writing process than they did on analysis. 
On average teachers spent significantly more time evaluating material, and the writing process, than they did on application and synthesis.

The findings suggest that teachers do use higher thinking skills. What was interesting, however, was the fact that evaluation was used more than analysis and synthesis which are the key building tools used to create originality.

\section{de Bono Six Hats}

On average, the teachers spent significantly more time in Blue Hat (Metacognition) than on other thinking types.

On average teachers spent considerably more time on Red Hat (Emotional) than on White (Objective) or Green (Creative) thinking.

The use of de Bono's model provides some useful information that is not considered under Blooms taxonomy. In the first place the model is able to distinguish between higher order thinking and metacognitive thinking. The fact that these teachers did not use analysis and synthesis to any great extent could have masked the fact that they were reflective, they did think about their thinking, they were holistic. This contrasts sharply with the findings of McGregor (1993) who found that students did not think metacognitively.

de Bono's model also identifies that the affective elements of the information process made so public throught the extensive work of Kuhlthau $(1993,1995)$ is very much to the fore in the lives of these teachers. Indeed the findings here which relate to the end stages of the information process demonstrate that teachers go through the roller coaster of uncertainty/certainty through to the conclusion of their information task.

\section{Self-efficacy}

The respondents have significant confidence in their ability to undertake information tasks, but more so in older than newer technologies. The analysis of practice showed that the respondents were not as aware of the complexity of the information process as they thought. In their self assessment and in practice respondents showed considerable doubt in their ability to undertake self-evaluation of their success.

No significant difference in findings were discovered when the respondents were divided into two groups, namely practicing but unqualified teacher librarians and class teachers.

\section{CONCLUSIONS (PRELIMINARY)}

The study indicates that teachers demonstrate much of the impoverished information behaviour shown by senior school students that has been identified by other studies. On the other hand teachers do demonstrate a more robust use of higher order thinking skills than portrayed by senior students. The study confirms the reliability of Kuhlthau's ISP particularly in terms of the affective cycle of uncertainty through certainty. The study also demonstrated that teachers are vague on issues of focus and closure. Like students teachers see the information task as one of finding the right answer rather than one of finding a good answer. 
The study suggests that caution should be taken in expectations that teacher librarians are equipped to role model good informing practice and act as role models for class teachers. It suggests that in writing about the role of the teacher librarian in developing an information literate school community it is important to distinguish between qualified and unqualified teacher librarians. What this study demonstrates is that unqualified teacher librarians are no better equipped to employ an information model that are their classroom colleagues. Whether or not qualified teacher librarians are equipped to act as informing mentor remains to be tested.

\section{REFERENCES}

Bloom, B. (1956). Taxonomy of educational objectives: The classification of educational goals. Handbook 1: Cognitive domain. NY: Longman.

Brake, T. (1986). Tools for learning (BLRD Report 5892) London: British Library.

Brake, T. (1980). The need to know: Tteaching the importance of information. (BLRD Report 5511) London: British Library.

Brown, J. (1998) Changing teaching practice to meet current expectations. Emergency Librarian, $16(2), 9-14$.

Candy, P. (1995 November). Major themes and future directions: Conference summary and implications. Paper presented at Learning for Life and the Autonomous Learner. Adelaide.

Charles Sturt University. ETL401 Introduction to teacher librarianship (1997). Subject Outline. Wagga Wagga: CSU.

Coggan, J., \& Foster, V. (1985). But my biro won't work: Literacy and learning in a secondary school classroom, an action research study. Adelaide: AATE.

CPT: Key to independent learning; teachers and teacher librarians cooperatively planning and teaching. (1988). Brisbane: LARS.

de Bono, E. (1987). Six thinking hats. London: Penguin.

Dillon, K. (1992). The professional development needs and concerns of rural secondary school teachers: implications for teacher librarian's. Unpublished masters thesis. Charles Sturt University.

Doyle, C. (1994). Information literacy in an information society: A concept for the information age. NY: ERIC.

Eisenberg, M., \& Brown, M. (1992). Current themes regarding library and information skills instruction: research supporting and research lacking. School Library Media Quarterly, 20 (2), 103-109.

Goodlad, J. (1990). Studying the education of educators: from conception to findings. Phi Delta Kappan, 71, 698-701.

Hall, N. (1986). Teachers, information and school libraries. Paris: Unesco.

Henri, J. (1997). Let's look after the teachers. School Libraries Worldwide, 3 (1), 31-38.

Henri, J., \& Hay, L. (1995 October). The principal's role in developing and supporting an information literate school community. Paper presented at the ASLA Conference. Fremantle. Hounsell, D., Martin, E., Needham, G., \& Jones, H. (1980). Educational information and the teacher. London: British Library.

Hughes, S. (1998). The teacher, teacher librarian, and critical thinking. In A meeting of the minds 2. Canberra: Australian School Library Association. 92-97

Juchau, M. (1984). Teachers information needs and the school library. Sydney:ALIA.

Kuhlthau, C. C. (1993). Seeking meaning: A process approach to library and information services. Norwood, NJ: Ablex. 
Kuhlthau, C. C. (1995). The process of learning from information. School Libraries Worldwide, 1 (1), 1-12.

Learning for the future (1993). Melbourne: Curriculum Corporation.

McGregor, J. (1993). Cognitive processes and the use of information: a qualitative study of higher order thinking skills used in the research process by students in a gifted program. Unpublished doctoral dissertation, Florida State University.

McGregor, J. (1994). An analysis of thinking in the research process. School Libraries in Canada, 14 (2), 4-7.

McGregor, J. (1995). Process or product: Constructing or reproducing knowledge. School Libraries Worldwide, 1 (1), 28-40

Moore, P. (1995). Information problem solving: A wider view of library skills. Contemporary Educational Psychology, 20, 1-31.

Moore, P. (1996). Information literacy: The importance of questions. Scan, 15 (1), 43-46.

Moore, P. (1998). Teaching information problem solving in primary schools. Wellington, NZ: Ministry of Education.

Moore, P. (1998a). Primary school children's interaction with library media: Information literacy in practice. In S. Shoham \& M. Yitzhaki. Education for All. Ramat-Gan, Israel: BarIlan University.

O'Connell, J. (1997). Seeking meaning: A study of teachers' perspectives of the information search process. Unpublished masters thesis. Charles Sturt University.

O'Connell, J. \& Henri, J. (1997). Information literacy: Teachers' perspectives of the information process. In L. Lighthall \& $\mathrm{K}$. Haycock. Information rich but knowledge poor: Emerging issues for schools and libraries worldwide. Seattle, WA: LASL. 125-136.

Pitts, J. (1994). Personal understandings and mental models of information: A qualitative study of factors associated with the information seeking and use of adolescents. Unpublished doctoral dissertation, Florida State University.

Swain, D. (1996). Information search process model: How freshmen begin research. proceedings of the 59th ASIS annual meeting. Medford, NJ: ASIS:95-99.

Wilson, K. (1997). Information skills: The reflections and perceptions of student teachers and related professionals. In L. Lighthall \& $\mathrm{K}$. Haycock. Information rich but knowledge poor: Emerging issues for schools and libraries worldwide. Seattle, WA: IASL. 63-74.

\section{RESOURCES:}

Bloom's Taxonomy of the Cognitive Domain http://www.tecweb.org/eddevel/blooms.html de Bono's Six Thinking Hats http://members.ozemail.com.au/ caveman/Creative/Techniques/sixhats.htm Kuhlthau's ISP http://www.library.arizona.edu/library/teams/infolit/InfoLit2000/Kuhlthau1.htm Ralf Schwarzer \& Matthias Jerusalem, Self Efficacy Scale http://www.yorku.ca/faculty/academic/schwarze/engscal.htm 